\title{
The quantum metaphor and the organization of words in the mind
}

\author{
Gary Libben
}

Received: 29 December 2014/Revised: 4 May 2015/Accepted: 11 May 2015/Published online: 17 March 2017

(C) The Author(s) 2017. This article is an open access publication

\begin{abstract}
The mental lexicon has served as an almost ideal meeting ground for the cognitive sciences. In order for research on lexical processing to fulfill its potential to provide the elusive links among brain, cognition and culture, it is necessary to re-examine the view that the mental lexicon is a knowledge store of discrete lexical items. I suggest that metaphors from quantum physics, in particular the notions of wave/particle duality and superposition, are extremely valuable to an understanding of the contents of the mental lexicon and to the framing of research methodologies. Taken together, these perspectives lead us away from the assumption that the mind/brain contains representations for words. What they lead us toward is the view that the observation of words in the world may not require the postulation of words in the mind/brain.
\end{abstract}

\section{The quantum metaphor and the organization of words in the mind}

At the time of writing, no research team has been able to look into the human brain and see a word. Yet, we all have a strong intuition that words are represented

\section{G. Libben $(\bowtie)$}

Brock University, 500 Glenridge Ave., St. Catherines, ON L2S 3A1, Canada

e-mail: Gary.libben@gmail.com there in some form or other. There are good reasons to hold this view. We learn words and we can recall them. We can point to objects and name them. Speakers of more than one language can name objects in one language and then provide a translation in another language. It seems obvious that this ability requires that speakers of a language possess a store of words, a mental lexicon, that is both cognitively and neurologically real.

Over the past decades, great progress has been made in understanding how words are represented in the mind. We have identified the fundamental patterns of word recognition, we have identified many of the lexical variables that modulate those patterns, we have constructed models that differentiate between the modalities of speech and reading, and we have developed findings that distinguish between the processing of morphologically simple words such as the English word board and its various related morphologically complex forms such as boarding, re-board, and boardroom. Finally, we have advanced the understanding of how words that are related to one another semantically both facilitate and inhibit one another in word recognition experiments (Baayen 2007; Libben et al. 2012).

These advances in knowledge and the many hundreds of psycholinguistic experiments that have been conducted over the last decades of research on words in the mind have now created a paradoxical and pivotal state of affairs in the field. The paradox is that the construct of the mental lexicon as a dictionary in 
the mind, which has enabled these advances, may need to be re-conceptualized in order to deal with them. But, this is also a pivotal opportunity to advance understanding. Just as the original introduction of the construct of the mental lexicon by Oldfield (1966) served to create an ideal meeting ground for the cognitive sciences, it may be the case that a reconceptualization of the mental lexicon can create the meeting ground that will enable the elusive links among the terms Brain, Cognition, and Culture. My goal in this paper is to present a framework for this reconceptualization.

\section{How do we need to re-conceptualize words in the mind}

Psycholinguists who work on the representation and processing of words in the mind and brain are well aware of the fact that it is very unlikely that anything like a desktop dictionary exists in the mind/brain. Yet, we expect that the memory store that we call the mental lexicon has many of the features of a desktop dictionary (Aitchison 2012). It would contain representations of the forms of words in both their written and spoken manifestations. It would either contain, or possess links to, meaning representations. It would provide an indication of whether a word contains morphological elements such as prefixes or suffixes, and it would allow links to other words that are related to it by virtue of their form and/or meaning.

These expected characteristics of the mental lexicon support a view of the mental lexicon as a dictionary in the mind. This dictionary would of course not be organized as an alphabetical listing. Indeed, it is relatively unlikely that it would be organized as a listing at all (but see Forster 1976, 2007).

Implicit in the discussion above is the assumption that it is scientifically profitable to analyze the ways in which the putative dictionary in our minds corresponds to attested dictionaries in the world. In many ways, this assumption seems warranted and attractive. The mental lexicon is the cognitive domain that links representations to one another. This is what dictionaries do. From the earliest times, what we call dictionaries have been lists of words. And from the fact that we have seen lists of words in the world, it seems plausible that there are lists (or at least stores) of words in the minds of people. Yet there is danger in the attractiveness of such an analogy. It might be the case that we only suspect that there are words in the mind because we are familiar with words in the world. This is a very natural tendency in the cognitive sciences, and one from which it is difficult to break free.

Consider, as an example, the case of writing systems. It seems intuitively obvious to literate speakers of English that words of their language are composed of consonants and vowels. The reason for this is straightforward. The writing system that is a concretization of the language presents it that way. But, on the other hand, using the same logic and the same type of evidence, a literate native speaker of Arabic or Hebrew would see (both literally and figuratively) words of his or her language as composed of consonants, because the writing system presents it that way. For readers of languages whose written forms use syllabaries, it would be the syllable. For readers of Chinese, it might be the logographic character, for readers of Korean, it might be the syllable structured into a CV-(C) template. In one way, such views carry with them fallacies supported by the allure of external concreteness. We see an external representation of a language and suppose that one reason for our ability to speak and understand the language is that we possess those external representations. In one way, as I discuss below, this is very unlikely to be true. It basically amounts to using a technological invention and then putting that invention back in our heads as a hypothesis about cognitive structure. In another way, however, it is not completely unreasonable. It is not an accident that English is written with vowels and consonants whereas Semitic languages such as Arabic and Hebrew rely on consonants for their representations. As technological innovations, the writing systems were created to meet the needs of language users and to accord with the properties of specific languages.

Now, how do principles and examples such as these relate back to words in the mind? It is very likely that we do the same things with words as we do with symbols of writing. It is not an accident that we have physical dictionaries that list words as discrete entities. They are likely to be the entities that most correspond to processes in the mind and brain. But, it is quite unlikely that they are those processes. Just because we have dictionaries in the world, does not mean that we can take these measurable external manifestations and 
assume that they are isomorphically represented in our minds. This is not particularly controversial. It is unlikely that any psycholinguist or neurolinguist working today would hold such a view of the relation between a dictionary and a mental lexicon. The next step in this line of reasoning, however, might be somewhat more controversial. This step concerns words themselves, those putative representations that make up the mental lexicon. It does not seem to me that we are safe in supposing that we have words, as words, in the mind. It seems to me more likely that the notion of a word as discrete concrete entity only has reality in the outside world of measureable language behaviour. This distinction between the observable world and an internal, less-visible one has been central in the study of cognition for much of the twentieth century. But, interestingly, as I will discuss below, there are very substantial parallels between the issues surrounding the representation of words in the mind and the issues that were dealt with by quantum physicists in the first part of the twentieth century. And, there is an interesting link between the history of quantum physics and the history of psychology.

\section{The quantum connection}

As Smith (2006) has brought to light, members of the first generation of quantum physicists all came from academic families with broad interests in both the humanities and natural sciences. Niels Bohr's father was a physiologist who was twice nominated for the Nobel Prize. Niels Bohr had strong connections to philosophy and had read a great deal of the work of William James. Indeed, he used James' notions of stream of consciousness in his understanding of the quantum world. As the work of Hunt (2001) and Smith (2006) reveal, it is not an accident that the metaphors used in the explanations of constructs in quantum physics such as wave/particle duality, uncertainty, and superposition are easily transferable to the psychological domain. Indeed, it is very likely that they came from that domain in the first place. Hunt (2001) provides a particularly revealing quote from Bohr (1934):

The unavoidable influence on atomic phenomena caused by observing them corresponds to the well-known change of the tinge of the psychological experiences which accompanies any direction of the attention to one of their various elements (Bohr 1934, p. 100).

This was very much the view of William James who drew an important distinction between the natural internal state of the mind as characterized by a dynamic and fluid consciousness and the much more 'particle-like' representations that we might try to capture from the stream of consciousness. James' (1890) characterization of such attempts employs images such as "trying to examine the structure of a snowflake by holding it in your warm hand", or trying to "turn on the light quickly enough to see how the darkness looks" Hunt (2001).

It seems to me that the challenge of understanding words in the mind may benefit greatly from an examination of the issues addressed by early quantum physicists as metaphors. It may be, for example, that words do not have any reality as separate entities in the mind, but rather exist as superstates that have specific realizations only when they are observed (Libben 2014). The notion of lexical superstates builds metaphorically on the claim within the quantum physics community that particles are in superposition until they are actually measured at one location or another. The notion of superposition is related to the claim of wave-particle duality in quantum physics. An, electron, for example, can be both particle and wave, despite the fact that these states seem intuitively to be mutually exclusive. When observed, an electron will show itself to have wave or particle properties, depending on which of these is measured. Up to the point of measurement, however, it can be said to be in superposition, being neither (and both) a wave or particle. According to what has come to be known as The Copenhagen Interpretation (Heisenberg, 1958), it is only at the point of observation that there is a resolution of the state of superposition (also referred to as the 'collapse of the wave function').

A related view for language, and one that I think has value, is that a word exists as a superstate until it is observed in one situation or another. In this case, the observation corresponds to an act of language use. Thus, to take the word wallpaper, as an example, it is a noun (e.g., brightly coloured wallpaper) when I use it as a noun, it is a verb (e.g., to wallpaper a room) when I use it as a verb) and it has morphological structure (e.g., wall-paper) when I link it to words such as wallflower or newspaper. 
It may also be the case that the idea that I possess the word wallpaper in my mind/brain at all, is illusory. Rather, it may be the case that the notion of a word as a particle-like entity only occurs as a result of observation in the acts of language production or comprehension and, in particular, conscious reflection on such acts.

The fact that we can use words in the world, even the fact that words may be extremely prominent in the world, does not mean that we need to postulate them existing as inherently particle-like entities in the mind. Indeed, in the case of the question of the underlying nature of lexical knowledge and ability, there is good reason to suspect that going from things in the world (especially if those things are artifacts of human creation) and then "placing" them in the mind, will lead us further away from, rather than closer to, a better approximation of the truth.

An excellent demonstration of how such an error can lead to a scientific dead-end can be seen in the brilliant, but ultimately incorrect, approach to the correspondence between mind and brain proposed by Franz Joseph Gall, who founded the school of phrenology in the late eighteenth century.

\section{Lessons from phrenology}

Franz Joseph Gall was born in 1758 and spent most of his professional life in Vienna, where he gained fame as a pioneer of brain dissection techniques and the analysis of the correspondence between personality traits, psychological functions, and discrete locations in the brain. Gall championed the view that the brain contained discrete organs of thought and that these were related to specific locations in the brain. His views gained great popularity in the British Isles and America in the first half of the nineteenth century and seemed to provide an almost perfect way to answer, and address scientifically, fundamental questions about the correspondence between the contents of mind and their physical basis in brain structure and function. The basic hypothesis, as formulated by Gall, was that cognitive organs or modules corresponded to faculties, abilities, and propensities. These would include very basic ones such as cautiousness, as well as higher ones such as benevolence, conscientiousness, wit and wonder. As seems evident, these are not distributed evenly across the population. Some people are wittier than others, some are more cautious than others. Some people seem to be more inclined than others to wonder. Gall's physical account for this was that the amount of the trait or ability possessed by a person would correspond to the size of that person's region of the brain that is associated with the trait or ability. He reasoned that increases in brain size in particular locations would place pressure on the skull from within and would be detectable to the trained phrenologist as topographical anomalies that could be felt through palpation of the skull.

By the mid-nineteenth century, phrenology was largely discredited as a pseudoscience. One reason for this was that much like hypnotism in later decades, phrenology turned out to be extremely prone to charlatanry. The most important reason, though, was that later evidence showed it to be wrong in its fundamental claims. The required replicable evidence in skull topography was not there. And, the fundamental claim of traits having existence as wholes in the brain emerged as an almost complete fallacy of misplaced concreteness. This did not negate, however, the validity of the claim that people demonstrate traits and that different people demonstrate them to different degrees. Certainly people exhibit cautiousness, conscientiousness, wit, and wonder. What we do not know is whether they actually possess these traits as traits. I would like to suggest that this is also our situation as researchers with respect to the notion of a mental lexicon, indeed with respect to the notion of word itself.

\section{Words in the mind and brain}

Let me suggest at the outset of this section that rather than talking about the representation or processing of words in the mind, we should be using alternative formulations such as "cognitive processing underlying word naming behaviour" or "cognitive processing underlying lexical decision performance" or "cognitive knowledge underlying sentence production behavior". Such formulations may help to keep us a safe distance from the fallacy of misplaced concreteness while at the same time highlighting the fact that the nature of the observation (in this case, the type of language behavior) cannot, as was made clear by Werner Heisenberg in his formulation of the uncertainty principle, be taken out of the equation. Seen 
from this perspective, every type of language behaviour and its observation in a psycholinguistic experiment shows us a particular way in which human language ability can be manifested in the world. Such a view leads us away from the expectation that we will ever find a one-to-one correspondence between manifested behavior and the contents of mind and brain, as the phrenological work of Franz Joseph Gall was intended to reveal.

The view rather leads us in the opposite directionthat is, away from one-to-one correspondences and toward research that calls into question the assumptions that we may have inherited from loaded formulations such as "the representation of words in the mind". Such research would include the work of Pulvermüler (2001), who has investigated the semantic properties of words and evidence regarding brain activation associated with their use. It also includes the work of Elman $(2004,2011)$ who has called into question whether we need to postulate a mental lexicon in order to understand lexical knowledge. In addition, it includes the research of Baayen and colleagues (e.g., Baayen 2010; Baayen et al. 2013) whose work on discriminative learning has challenged the need to postulate mental representations for morphemes as meaningful sub-elements of words.

\section{Methods are not neutral}

One of the most important early insights in quantum physics was that it is almost impossible to separate the method of observation from that which is observed. Against this background, it is very unlikely that such methodological neutrality will be achieved in psycholinguistics or any other branch of research on human cognition.

There is reason to believe that the study of lexical processing is moving to a state of much greater adequacy on the methodological front. At the turn of the millennium, Libben and Jarema (2002) noted that experimental research on the mental lexicon was almost fully dominated by a single task, the lexical decision task. Currently, investigations of lexicon processing are much more varied, often incorporating a variety of tasks that yield rich datasets (Libben et al. 2012a, b).

It is important to note that if the quantum perspective does in fact have relevance to current research on lexical processing, it is not the case that new methods, even if they are much more ecologically valid, will be without drawbacks. By definition, the methods will always colour our understanding of the nature of reality. In fact, they are an inextricable component of that reality. Thus, there are no neutral methods. A brief discussion of the lexical decision task offers an illustrative example of this.

The lexical decision task was introduced into the psycholinguistic literature by Meyer and Schwanefeldt (1971). The task was almost the perfect vehicle for developing a form-based theory of words in the mind - that is, a theory of the mental lexicon. In its most common visual format, it requires that a participant see a word presented on a computer screen and then indicate as quickly as possible (by pressing a button labeled "yes" or "no") whether or not the word on the screen is an existing word. Thus, it is a task that asks participants to answer the question: Is this word in your mental lexicon?

Almost everything about the lexical decision task is consistent with the particle-like view of words in the mind. It constitutes a valuable demonstration of how a method frames the kinds of questions that can be asked and the kinds of answers that can be obtained. The lexical decision task typically presents single words to be classified. The task employs the type of logic of response time in cognitive research pioneered by Donders (1969) and Cattell (1886). It typically deals with the isolated word form as an element. In this way, the lexical decision task biases research about the nature of words in the mind in the direction of words as particle-like entities. As the lexical decision task demonstrates, it is possible to present words in isolation on a screen. It is possible to have language users reliably indicate whether they are 'in possession' of these words. But whether that which is possessed in the mind/brain is actually a word form may be another matter entirely.

\section{Focusing on potential forms in the modeling of mental lexical knowledge}

At the outset of this paper, I noted that no research team has yet looked into a human brain and seen a word. If indeed the quantum metaphor for the representation of words in the mind is correct, we should expect that words, as words, in the mind/brain 
neither have been seen nor will be seen. The nature of the human capacity for language is much too subtle to employ a simple store of units. Yet it is obvious that we do have lexical knowledge. And, to advance our understanding of that lexical knowledge, representations in the mind are required. What is needed is a means by which we can conceptualize words in the mind in a manner that is concrete enough to provide a scaffolding for knowledge advancement and also dissimilar enough from words on pages, or dictionaries on desks to enable us to maintain a safe distance from the fallacy of misplaced concreteness.

In discussing the notion of how lexical superstate representations may differ from standard notions of words in the mind, I utilized as an example the compound word wallpaper. Indeed, I would like to suggest that compound words offer an extremely useful class of lexical structures with which to explore lexical and morphological superstates. The reason for this is that they are used as single words, but they also clearly have internal structure and links to other words. So, compound words enable us to consider words and their properties in the morphological domain in a relatively stable and generalizable manner. The stability and generalizability come from the prevalence and comparability of compound words across the world's languages. Compounding is the most common word formation process (Dressler 2006). Moreover, the major morphological constituents of compound words are lexical, so by using compounds as core examples we can avoid some of the challenges associated with the question of whether there are separate morphological representations for elements such as com-, par-, -able and -ity in suffixed words such as comparability.

So what can we learn from considering what mental representations and processes may be related to our ability to understand and produce compound words such as wallpaper? It seems to me that the first thing that would be learned is that words may have specific grammatical and semantic properties only when used in speech and comprehension by a specific person at a specific time and place. At bottom, those properties are psychological in nature and derive from individual language experience. As William James (1890) stressed, it is experience that is at the core of our cognitive ability. So, people will differ in how they represent a word such as wallpaper. For some, it may have both noun and verb readings, because they have experience in hearing, seeing, or producing it as both. For other people, it may have only a single grammatical function. And, the cultural associations will differ from person to person quite a bit more. For some people, the compounds wallpaper and wallflower will be related in the mind. For others less so, if their dominant meaning association to the term wallflower is not the southern European plant, but rather the idiomatic meaning of a person who does not have a dance partner, and who is generally shy or socially awkward.

As the above discussion suggests, it is very difficult to talk about words without ascribing a mental reality to them. As has been evident throughout our discussion, they clearly do have mental reality, but that reality may be quite different from the form of the words that we see on a page. Now, how can we then use the notion of word in psycholinguistic discourse, given the fact that our primary tools for the external representation of lexical knowledge are precisely those 'words on a page'? I think that our best approach is to think of words as encapsulating a set of possibilities that may or may not be manifested by individual speakers of a language. Lexical knowledge is much more than that which is committed to memory. It is the dynamic system that enables lexical creativity, growth, and refinement. Thus, a word is not simply a representation of lexical knowledge possessed in the mind/brain. It is a representation of lexical possibilities enabled by the mind/brain.

\section{Summary}

In the sections above, I have suggested that the construct of a mental lexicon, which has served to advance the field of psycholinguistics so significantly over the past four decades is in need of fundamental reconceptualization. I suggest that indeed it is the intuitive relation to lexicons in the external world that places it in need of such re-examination.

I have also claimed that there are critical features of research on lexical processing that give it metaphorical comparability to research in quantum physics. I stress the term metaphorical to underline the fact that this type of proposal is distinct from proposals that have linked quantum constructs to actual brain structures and the material basis of consciousness (e.g., Penrose 1994). 
A consideration of the constructs of quantum physics that seem to have immediate application to research on lexical processing provides a framework within which to move beyond a re-conceptualization of the mental lexicon to a re-examination of the view that we have words in the mind. It may be the case that, until they are actually used in productions, what we call words in the mind exist only as potentials for realization as specific items with semantic and formal characteristics. Thus, the fact that words may have specific properties at the time of observation, does not require that they have single or specific representations in the mind. It would be neater and tidier and perhaps more economical if this were the case. But there is little reason to believe that the mental system that serves lexical knowledge is designed to be neat, tidy, or economical. Much more likely is that the cognitive system is organized to maximize our capacity to create meaningful utterances and to understand them. If this is the case, it is preferable to consider the mental lexicon, not a the store of words in the mind, but rather as that cognitive system that constitutes an individual's capacity to produce and comprehend words across modalities and across contexts. The lexical system does not need to possess words in order to use words.

Acknowledgements Open access funding provided by University of Vienna. The development of this publication was supported by the "Words in the World" Partnership Project funded by the Social Sciences and Humanities Research Council of Canada. Gary Libben is Guest Professor, Department of Linguistics, University of Vienna (Winter 2017).

Open Access This article is distributed under the terms of the Creative Commons Attribution 4.0 International License (http:// creativecommons.org/licenses/by/4.0/), which permits unrestricted use, distribution, and reproduction in any medium, provided you give appropriate credit to the original author(s) and the source, provide a link to the Creative Commons license, and indicate if changes were made.

\section{References}

Aitchison, J. (2012). Words in the mind: An introduction to the mental lexicon (4th ed.). Oxford: Wiley Blackwell Publishing.

Baayen, R. H. (2007). Storage and computation in the mental lexicon. In G. Jarema \& G. Libben (Eds.), The mental lexicon: core perspectives (pp. 81-104). Amsterdam: Elsevier.

Baayen, R. H. (2010). Demythologizing the word frequency effect: A discriminative learning perspective. The Mental Lexicon, 5, 436-461.
Baayen, R. H., Hendrix, P., \& Ramscar, M. (2013). Sidestepping the combinatorial explosion: Towards a processing model based on discriminative learning. Language and Speech, 56, 329-347.

Bohr, N. (1934). Atomic theory and the description of nature. Cambridge: Cambridge University Press.

Cattell, J. M. (1886). The time it takes to see and name objects. Mind, 11(41), 63-65.

Donders, F. C. (1969). On the speed of mental processes. In W. G. Koster (Ed.), Attention and performance II. Acta psychologica (vol. 30, pp. 412-431). (Translation of "Over de snelheid van psychische processen. Onderzoekingen gedaan in het Physiologisch Laboratorium der Utrechtsche Hoogeschool, 1868-1869, Tweede reeks, II, 92-120").

Dressler, W. U. (2006). Compound types. In G. Libben \& G. Jarema (Eds.). The representation and processing of compound words (pp. 23-44). Oxford: Oxford University Press.

Elman, J. L. (2004). An alternative view of the mental lexicon. Trends in Cognitive Sciences, 8(7), 301-306.

Elman, J. L. (2011). Lexical knowledge without a lexicon? The mental lexicon, 6(1), 1-33.

Forster, K. I. (1976). Accessing the mental lexicon. In R. J. Wales \& E. Walker (Eds.), New approaches to language mechanisms (pp. 257-287). Amsterdam: North-Holland.

Forster, K. I. (2007). Visual word recognition: Problems and issues. In G. Jarema \& G. Libben (Eds.), Core perspectives on the mental lexicon. Oxford: Elsevier.

Heisenberg, W. (1958). Physics and philosophy: The revolution in modern science. New York: Prometheus Books.

Hunt, H. T. (2001). Some perils of quantum consciousnessEpistemological pan-experientialism and the emergencesubmergence of consciousness. Journal of Consciousness Studies, 8, 35-45.

James, W. (1890). The principles of psychology. New York: Dover.

Libben, G. (2014). The nature of compounds: A psychocentric perspective. Cognitive Neuropsychology, 31, 8-25.

Libben, G., \& Jarema, G. (2002). Mental lexicon research in the new millennium. Brain and Language, 81, 1-10.

Libben, G., Weber, S., \& Miwa, K. (2012a). P3: A technique for the study of perception, production, and participant properties. The Mental Lexicon, 7(2), 237-248.

Libben, G., Westbury, C., \& Jarema, G. (2012b). Embracing complexity. In G. Libben, G. Jarema, \& C. Westbury (Eds.), Methodological and analytic frontiers in lexical research (pp. 1-12). Amsterdam: John Benjamins.

Meyer, D. E., \& Schvaneveldt, R. W. (1971). Facilitation in recognizing pairs of words: Evidence of a dependence between retrieval operations. Journal of Experimental Psychology, 90, 227-234.

Oldfield, R. C. (1966). Things, words and the brain. $Q J$ Exp Psychol, 18(4), 340-353.

Penrose, R. (1994). Shadows of the mind: a search for the missing science of consciousness. New York: Oxford University Press.

Pulvermüller, F. (2001). Brain reflections of words and their meaning. Trends in Cognitive Sciences, 5(12), 517-524.

Smith, C. U. (2006). The 'hard problem' and the quantum physicists. Part 1: The first generation. Brain and Cognition, 61(2), 181-188. 